\title{
Local anesthetics and advances in their administration - an overview
}

\author{
Robert M Jung ${ }^{1}$, Magdalena A Rybak ${ }^{1}$, Paweł T Milner ${ }^{1}$, Natalia Lewkowicz ${ }^{1}$ \\ ${ }^{1}$ Department of General Dentistry, Medical University of Lodz, Poland
}

Jung RM, Rybak MA, Milner PT, Lewkowicz N. Local anesthetics and advances in their administration - an overview. J Pre-Clin Clin Res. 2017; 11(1): 94-101. doi: $10.26444 / j p c c r / 75153$

\begin{abstract}
In dentistry nowadays, local anesthesia is the standard and the backbone for controlling pain Every year, researchers seek and develop new ways in which pain can be alleviated and managed better to ensure patient comfort by focusing on improving aspects such as anaesthetic agents, delivery devices and the techniques involved. The introduction of newer techniques assists dentists in providing enhanced pain relief with reduced pain from injection and fewer adverse reactions. Objective. The purpose of this overview is to highlight the mechanism and efficacy of certain anaesthetic agents, emphasizing complications associated with local anesthesia, as well as the modern techniques that have been developed to improve patient comfort and reduce pain while performing anaesthesia.
\end{abstract}

\section{Key words}

local anaesthesia, pain control, wand, sleeperone, quicksleeper, syringe micro vibrator

\section{Abbreviations}

PDL - Periodontal Ligament; LA - local anaesthesia; FDA - Federal Drug Administration; CCLAD - Computer-Controlled Local Anaesthetic Delivery; P-ASA - palatal anterior superior alveolar; AMSA - anterior and middle superior alveolar; STA Single-Tooth Anaesthesia System; CNS - Central Nervous System; PAR - Permanent Analysis of Resistance; SMV - Syringe micro vibrator

\section{INTRODUCTION}

One of the most important skills for dental practitioners to attain is the ability to provide safe and effective local anaesthesia (LA). The injection is perhaps the greatest source of fear among patients, which results in the problem of fear of needles (trypanophobia) which, in turn, may lead to syncope or other medical emergencies during the injection of a local anaesthetic [1]. A combination of factors, including knowledge of the agents used, the anatomy involved, modern techniques, devices and proper deposition of the local anesthetics while performing nerve blocks (close to the nerve in order to obtain optimal diffusion, but without causing mechanical trauma), will result in profound anaesthesia and a pain-free dental experience $[1,2]$. The mechanism of local anaesthetics is to interrupt the conduction of a nerve impulse by inhibiting sodium ion influx within neuron membranes [3]. Local anaesthestics have a high affinity for receptors within sodium channels. As a result, the threshold potential level will not be reached and thus an action potential will not occur.

\section{OBJECTIVE}

The aim and objective of this overview is to summarize and collate important information for dentists regarding the use of commonly used anaesthetic agents, elaborating on their efficacy and mechanisms, as well as the complications associated with local anaesthesia. The overview also discusses the techniques and modern devices used nowadays in order to

Address for correspondence: Robert M Jung, Department of General Dentistry, Medical University of Lodz, Poland

E-mail: rob.jung92@gmail.com

Received: 19 February 2017; accepted: 20 April 2017 reduce pain while performing anaesthesia, thereby resulting in improved patient comfort.

Most popular local anaesthetic agents. Local anaesthetics used in dentistry fall into two groups: esters (benzocaine, procaine) and amides (lidocaine, articaine, bupivacaine, prilocaine, mepivacaine). Amides are used more frequently compared to esters, as amides produce a more rapid and profound anaesthetic effect. Esters are no longer produced in injectable form.

Lidocaine is the most common local anaesthetic to be used in dentistry. It was developed in 1943 and introduced into the market in 1948 by Nils Lofgren. It is characterized by a rapid onset of action and intermediate duration of efficacy. As a result, lidocaine is suitable for surface, infiltration and block anaesthesia. Lidocaine is usually used at a $2 \%$ concentration. The onset of lidocaine is about 45-90 s and its duration of action is $10-20 \mathrm{~min}$. It is about $95 \%$ metabolized in the liver [4].

Articaine. Originally called 'Carticaine', it was first prepared by Rusching et al. in 1969. It is the only amide local anesthetic that contains a thiophene ring and an additional ester ring. The thiophene ring increases its lipid solubility which, in turn, makes it highly diffusible and effective at penetrating tissues, and $95 \%$ is plasma protein bound. The presence of the amide and ester linkage reduces the risk of overdosing, which could lead to a toxic reaction. Elimination of articaine is through the kidneys [5]. Many local anaesthetics have epinephrine added to them to cause vasoconstriction of the neighbouring capillaries, which results in slower absorption of the anaesthetic and increased the time of action. Articaine is usually used at a $4 \%$ concentration. 
Bupivacaine. Synthesized in 1957 by Ekenstam and was first used in a clinical setting in 1963. It is constructed with a longer side chain with four methylene groups on the piperidine ring that is responsible for the different properties of bupivacaine, compared to lignocaine. The onset of bupivacaine ranges from 1-17 $\mathrm{min}$ and the duration of action lasts 2-9 h. The duration of anaesthesia is significantly longer with Bupivacaine than with any other commonly used local anesthetic. It is usually used at a $0.5 \%$ concentration [6].

Mepivacaine. First introduced into dentistry in 1960 as a 2\% solution containing vasoconstrictor levonordefrin. In 1961, a $3 \%$ solution without any vasoconstrictor was developed. Mepivacaine has a very similar anaesthetic potency to lidocaine, but also has milder vasodilating ability, which leads to a longer duration of anaesthesia without the use of a vasoconstrictor. Mepivacaine is the third most widely used local anesthetic in dentistry after lidocaine and articaine. In dentistry, mepivacaine is available as a $3 \%$ solution without vasoconstrictors or as a $2 \%$ solution with vasoconstrictors [7].

Prilocaine was introduced to the market in 1965. It is less toxic and less potent than mepivacaine or lidocaine and provides a slightly longer duration of action. It is available as $4 \%$ prilocaine with epinephrine and as plain $4 \%$ prilocaine [8]. There have been reports that the administration of prilocaine in children may induce methemoglobinaemia. This is a condition that affects oxygen levels in the blood [9]. As a result, prilocaine should not be used in children younger than 6-months old, pregnant women, or in patients taking oxidizing drugs. Practitioners should be vigilant of the dosing guidelines in order to ensure patient safety [10].

Vasoconstrictors. The combination of vasoconstrictors and local anaesthetics result in an increased duration of action as well as providing reasonable haemostasis of the operating field. Epinephrine is contraindicated in patients with hyperthyroidism. Vasoconstrictors delay absorption, subsequently decreasing systemic toxicity. Substances such as adrenaline work by stimulating the alpha-1 adrenergic receptors of the submucosal vasculature. However, the use of vasoconstrictors can have negative effects. By reducing the blood flow to the site, the $\mathrm{pH}$ of the tissue is also reduced. This results in a shift of the equilibrium towards the ionized form of the anaesthetic, the anaesthetic solution is therefore unable to penetrate the membrane as well, resulting in a diminished anesthetic effect. Decreased blood flow could potentially result in delayed healing of a wound. Additionally, the socalled 'rebound effect' may take place after the vasoconstrictor has worn off, which is where increased blood flow and the aggregation of the degradation products results in a secondary haemorrhage [11]. Levonordefrin is also used as a vasoconstrictor in local anaesthesia. It provides significantly less haemostasis compared to epinephrine, and is contraindicated in patients who are taking tricyclic antidepressants [8].

Duration of local anesthetics. Table 1 shows the time of onset of popular anesthetic solutions with different concentrations of vasoconstrictors, as well as the duration of pulpal and soft tissue anesthesia.

Adverse effects. Local anaesthetics are generally safe when used appropriately in the appropriate doses and
Table 1. Intermediate duration of action of local anesthetics in the US

\begin{tabular}{|c|c|c|c|c|}
\hline Agent & & Onset & Pulpal & Soft Tissue \\
\hline Articaine & Epinephrine & & & \\
\hline $4 \%$ & $1: 100,000$ & $1-2 \min$ & $60-75 \min$ & $3-6 \mathrm{hrs}$ \\
\hline $4 \%$ & $1: 200,000$ & $1-2 \min$ & $45-60 \mathrm{~min}$ & $2-5 \mathrm{hrs}$ \\
\hline Lidocaine & Epinephrine & & & \\
\hline $2 \%$ & $1: 100,000$ & $2-3 \min$ & $60 \mathrm{~min}$ & $3-5$ hrs \\
\hline Mepivacaine & Levonordefrin & & & \\
\hline $2 \%$ & $1: 20,000$ & $1.5-2 \mathrm{~min}$ & $60 \mathrm{~min}$ & $3-5 \mathrm{hrs}$ \\
\hline Prilocaine & Epinephrine & & & \\
\hline $4 \%$ & $1: 200,000$ & $2-4 \min$ & $60-90 \mathrm{~min}$ & $3-8$ hrs \\
\hline $4 \%$ plain & None & $2-4 \min$ & $40-60 \mathrm{~min}$ (block) & $2-4 \mathrm{hrs}$ \\
\hline
\end{tabular}

Source: Malamed SF, Daniel L: 'Handbook of Local Anesthesia', p.79 [12].

concentrations. However, they are capable of producing local and systemic toxicity $[13,14]$. Minor adverse effects may include post-procedural pain, headache, facial oedema, infections, gingivitis and transient paresthesia [5]. Ischemic necrosis may also occur following an injection of a local anaesthetic due to a combination of the irritability of the agent itself, the pressure with which the agent is injected, and the amount of constriction caused by the vasopressors [14]. This is noticed amongst patients undergoing local anaesthesia of the hard palate. Overdosing on local anaesthetics may cause unconsciousness, apnoea, hypotention, hypoxia, bradycardia, and potentially seizures [5]. Concentrations of $2-3 \%$ lidocaine carry little risk of producing toxicity, although formulations of $4 \%$ articaine and prilocaine have an increased risk. When $4 \%$ articaine was first submitted to the Federal Drug Administration (FDA) for approval from the in the United States, it was identified as having a higher risk for paresthesia than $2 \%$ lidocaine [14]. Although allergic reactions are quite rare, some patients - especially asthmatics - have hypersensitivity reactions to bisulfite preservatives. Bisulfites are also commonly found in food and drinks and are added to local anaesthetic cartridges [8]. Benzocaine and prilocaine have been shown to induce methemoglobinaemia, which is a process where iron in haemoglobin is altered, reducing its oxygen-carrying capability. This may produce cyanosis and symptoms of hypoxia. Prilocaine's metabolite, o-toluidine, is known to cause methemoglobinaemia.

\section{Most common complications after local anaesthesia delivery and suggested treatment}

Local complications when administering local anaesthesia include blanching, haematoma, trismus, needle breakage, insufficient anaesthesia and excessive spread of the anaesthesia. There are many predisposing factors to toxic reactions that may occur when administering the LA. Absorption, metabolism, and excretion are not fully developed in patients under the age of six, and in those over the age of 65 these functions are not as effective. With regard to underweight patients, especially those with little muscle mass, their tolerance to the drug is reduced. Most local anaesthetics are bio-transformed in the liver and broken down to products that can be eliminated from the body by the kidneys. Liver damage reduces the liver's ability to degrade the drug, resulting in increased blood levels of the anaesthetic. Serum cholinesterase is an enzyme produced in the liver required for biotransformation of ester local 
anaesthetics. If it is genetically missing, an overdose can result in increased blood levels. If the kidneys cannot eliminate the byproducts of local anaesthetics, there can be toxic accumulations in the blood. During pregnancy, kidney functions can be disturbed, resulting in impaired excretion and increased blood levels of the anaesthetic [15]. Systemic toxic complications may occur when overdosing on local anaesthetics. Toxicity usually occurs in the cardiovascular system and the central nervous system (CNS). Stimulation of the CNS results in a toxic vasoconstrictory reaction, characterized by tachycardia, apprehension, sweating and hyperactivity. Depression of the CNS may follow, resulting in bradycardia, hypoxia and respiratory arrest [16].

Maximum safe doses for local anaesthetic agents for adults. The Table below shows the maximum doses of anaesthetics with or without epinephrine in healthy adults. Bupivacaine is known to have the longest duration of all local anaesthetics. According to Malamed SF, lidocaine's maximum dose is $3 \mathrm{mg} / \mathrm{kg}$ and $5 \mathrm{mg} / \mathrm{kg}$ with epinephrine. In other literature, lidocaine's maximum dose with epinephrine is $7 \mathrm{mg} / \mathrm{kg}$ [11].

Articaine is a popular anesthetic, characterized by

Table 2. Benko K: 'Clinical Characteristics of Local Anesthetics - Fixing Faces Painlessly: Facial Anesthesia in Emergency Medicine', in: EBMedicine, Vol. 11, No. 12, (December 2009) [13]

\begin{tabular}{lcccc}
\hline Agent & Onset & Duration & $\begin{array}{c}\text { Maximum } \\
\text { dose }\end{array}$ & $\begin{array}{c}\text { Maximum } \\
\text { Epinephrine dose }\end{array}$ \\
\hline Bupivacaine & $5-10 \mathrm{~min}$ & $\begin{array}{c}200 \mathrm{~min}+\text { (up } \\
\text { to } 540 \text { min w/ } \\
\text { epinephrine) }\end{array}$ & $2.5 \mathrm{mg} / \mathrm{kg}$ & $3 \mathrm{mg} / \mathrm{kg}$ \\
\hline Lidocaine & $<2 \mathrm{~min}$ & $\begin{array}{c}30-60 \text { min (longer } \\
\text { w/epinephrine) }\end{array}$ & $3 \mathrm{mg} / \mathrm{kg}$ & $5 \mathrm{mg} / \mathrm{kg}$ \\
\hline Articaine & $2-3 \mathrm{~min}$ & $180-360 \mathrm{~min}$ & $7 \mathrm{mg} / \mathrm{kg}$ & $7 \mathrm{mg} / \mathrm{kg}$ \\
\hline Mepivacaine & $3-5 \mathrm{~min}$ & $45-90 \mathrm{~min}$ & $5-6 \mathrm{mg} / \mathrm{kg}$ & $5 \mathrm{mg} / \mathrm{kg}$ \\
\hline Prilocaine & $5 \mathrm{~min}$ & $30-90 \mathrm{~min}$ & $5 \mathrm{mg} / \mathrm{kg}$ & $7 \mathrm{mg} / \mathrm{kg}$ \\
\hline Ropivacaine & $5-15 \mathrm{~min}$ & $200 \mathrm{~min}+$ & $3 \mathrm{mg} / \mathrm{kg}$ & $3 \mathrm{mg} / \mathrm{kg}$ \\
\hline Procaine & $10-20 \mathrm{~min}$ & $40 \mathrm{~min}$ & $7 \mathrm{mg} / \mathrm{kg}$ & Not applicable \\
\hline
\end{tabular}

relatively quick onset similar to lidocaine, but with longer duration of anaesthesia.

\section{Maximum safe doses for local anaesthetic agents for} children.

Table 3. Maximum dosage of local anesthetic solutions

\begin{tabular}{|c|c|}
\hline Anesthetic Agent & Maximum Dose \\
\hline 2\% Lidocaine & $3 \mathrm{mg} / \mathrm{kg}$ \\
\hline $2 \%$ Lidocaine with 100,000 adrenaline & $7 \mathrm{mg} / \mathrm{kg}$ \\
\hline $4 \%$ Prilocaine plain & $6 \mathrm{mg} / \mathrm{kg}$ \\
\hline $4 \%$ Prilocaine with felypressin & $9 \mathrm{mg} / \mathrm{kg}$ \\
\hline $0.5 \%$ Bupivacaine with $1: 200,000$ adrenaline & $2 \mathrm{mg} / \mathrm{kg}$ \\
\hline $\begin{array}{l}\text { 4\% Articaine with adrenaline 1:100,000 (approximately } 1.5 \\
\text { cartridge of } 2.2 \mathrm{~mL} \text { in } 20 \mathrm{~kg} \text { child) }\end{array}$ & $7 \mathrm{mg} / \mathrm{kg}$ \\
\hline \multicolumn{2}{|c|}{$\begin{array}{l}\text { Calculation of local anaesthetic dosage: } \\
2 \% \text { lidocaine }=20 \mathrm{mg} / \mathrm{mL} \\
2.2 \mathrm{~mL} / \text { carpule }=44 \mathrm{mg} / \text { carpule } \\
\text { A } 20 \mathrm{~kg} \text { child (approximately } 5 \text { years old) can tolerate a maximum dose of } 2 \% \\
\text { lidocaine with vasoconstrictor of: } \\
7 \mathrm{mg} / \mathrm{kg} \times 20 \mathrm{~kg}=140 \mathrm{mg} \text { Equivalent of } 3 \text { carpules }(6.6 \mathrm{~mL})\end{array}$} \\
\hline
\end{tabular}

\section{Instrumentarium for local anaesthesia delivery}

Glass Cartridges. Contain an anesthetic solution, supplied in $1.7-1.8 \mathrm{ml}$ sizes. In the UK, $2.2 \mathrm{ml}$ cartridges are available. The name, composition, vasoconstrictor presence and concentration are printed either on the glass cartridge itself, or on a plastic foil. The plastic foil acts as a safety feature in case the glass cartridge breaks inside the oral cavity, and holds the fragments together. Cartridges are usually pre-sterilized during fabrication and are ready to use after removal of the protecting foil. The cartridge packs may be kept at room temperature but away from direct sunlight and heat to avoid deterioration [11].

Needles. Those usually used in local anesthesia are supplied in 3 sizes and are meant for single use only: $12 \mathrm{~mm}$ extra short (used for intraligamentary techniques), $25 \mathrm{~mm}$ short (used for infiltration anaesthesia), and $36 \mathrm{~mm}$ long (used for regional nerve blocks). The diameter or lumen of the needle is referred to as the gauge, where the smaller the gauge number the larger the diameter of the needle. Using a 30 gauge needles makes aspiration very difficult to perform [11]. When performing anaesthesia, it is important to aspirate to prevent accidental intravascular injection. The needles also deflect very easily and have a high risk of breaking, compared to 25 gauge needles [1]. The cause of pain of the injection is due to several factors, such as: needle pressure, outflow speed of the solution, temperature and $\mathrm{pH}$ of the solution. During infiltrative techniques, local trauma to the periosteum may occur by introducing the needle into the tissues and releasing the solution under high pressure, resulting in significant pain. This may be avoided by slowly injecting the anaesthetic solution submucosally in a tunnel of anaesthesia, without touching the periosteum with the needle [11].

Syringes. Commonly used in Dentistry. Some have the ability to be sterilized and are generally made of rustproof steel. Plastic disposable needles are also available. There also exist several types of cartridge syringes: the insert type and the snap-in type. Both have a few common features. A screw thread at the front of the cartridge which allows the mantle of the needle to be screwed, and a ring at the back of the syringe to aid with aspiration. They also have a spring mechanism that facilitates with automatic aspiration. Occasionally, when aspirating, blood appears in the cartridge due entry into a blood vessel. In this situation, the cartridge is replaced with a new one to avoid the risk of infection intravasally, and also in order to determine whether the vessel has been penetrated again following subsequent anaesthesia. The intraligamental syringe (Fig. 1) works in such a way that light pressure is applied to the handle, enabling a strong and consistent outflow of the anaesthetic solution. The metal frame surrounds the glass cartridge to reduce the risk of breaking [11].

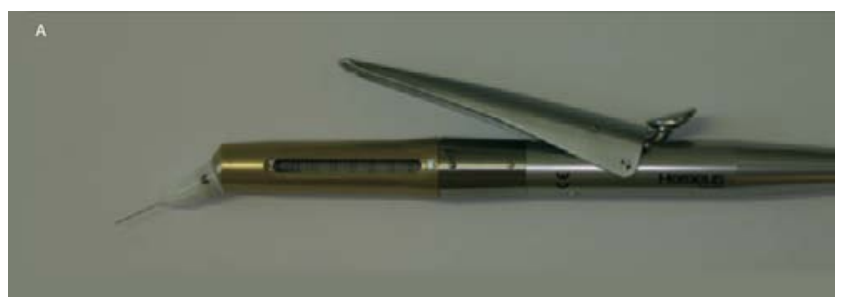

Figure 1. Intraligamentary anaesthetic syringe (Citoject, Heraeus) [11] 
Modern devices. Many devices have been developed in order to assist the dental practitioner to provide comfort against the fear, anxiety and pain associated with local anaesthesia administration experienced by the patient. In the mid-1990's, computer regulated local anaesthetic delivery systems were developed to control the rate of flow of the anaesthetic solution through the needle. Today, this is known as ComputerControlled Local Anaesthetic Delivery (CCLAD). In 1997, devices such as The Wand and Compudent were introduced. In the 2000's, devices such as the Control Syringe (Dentsply International, York, PA, USA), Quicksleeper and Sleeperone (Dental HiTec, Cholet, France) and Anaeject (Nippin Shika Takuhinm Shimonoseki, Japan) were introduced to the market [2].

Wand / Compudent System. Designed to enable the dental practitioner to manipulate the needle placement very accurately and administer the LA with the assistance of a foot-activated pedal. It was designed to be held like a pen, which naturally provides the practitioner with a greater tactile sensation and control compared to the traditional syringe. The Delivery of the LA is controlled by a computer resulting in a significantly improved injection experience. Although this device uses standard cartridges, for each patient it requires additional single-use set consisting of a plastic tube and a needle holder.

Single-Tooth Anaesthesia System (STA). Designed in 2006 by the manufacturers of the Wand It uses dynamicpressure sensing technology which monitors the exit pressure of the local anaesthesia solution in real time during its administration. It was originally developed to be used in Epidural Regional Anaesthesia; however, it has been adapted for use in dentistry to overcome the issues associated with periodontal ligament (PDL), anterior and middle superior alveolar (AMSA) and palatal anterior superior alveolar (P-ASA) injections. It is also used for traditional intraoral injection techniques. The STA includes a training mode, which verbally explains to the dental practitioner how to use the device properly. The benefits of this system include administration of a greater volume of LA with increased comfort to the patient, as well as less tissue damage, that may otherwise be encountered with the use of traditional syringes or periodontal ligament pressure devices [2].

Comfort Control Syringe. An electronic anaesthesia delivery device that administers the solution in two phases. Initially, the anaesthetic is injected slowly, and the rate of flow then increased to a preprogrammed rate chosen by the dentist. The practitioner operates the initiation, termination, aspiration and flow rate of the injection, using the button on the handpiece [1].

Quicksleeper system is a type of intraosseous anesthesia technique where it combines the electronic rotation of the needle for bone penetration and anaesthetic solution release. It features 4-programmed injection speeds and thanks to the electronic control, the tissues aren't over over-heated and the anaesthetic solution can be released slowly resulting in patient comfort during the injection [18]. It is an interesting alternative to the classic nerve block technique, especially inferior alveolar nerve blocks. This technique may potentially produce some complications, such as paresthesia, damage to a vessel and intraosseous hematoma. It may be a good alternative for alveolar inferior nerve blocks, however additional theoretical and practical training before using it is recommended for the operator.

SleeperOne. Designed by Dental HiTec in Cholet, France. According to the manufacturer, it can be used in regular infiltrative injections as well as intraligamentary, intraseptal, palatal and nerve block techniques. The device essentially looks like a pen, is gripped like one, has four injection speeds, and the deposition of the anaesthetic is controlled by a wireless foot pedal. This ensures higher precision when performing an injection than that of a standard syringe. The SleeperOne system mechanism involves Permanent Analysis of Resistance (PAR), which results in a constant control and monitoring of tissue resistance. The dose and rate of administration of the anaesthetic is controlled in order not to exceed the pain-threshold $[19,20]$. With regard to intraseptal injection, the SleeperOne is supplied with a double-beveled needle, which allows easier penetration to the bone. The intercrestal and cancellous bone is thin and sparse in children which enables the needle to be placed into the bone easily and the injection performed with minimal pressure [20]. For this reason, the SleeperOne device is becoming popular in paediatric dentistry. Its use for intraligamental anaesthesia in adults is also indicated, allowing good control of the needle while introducing it into the ligamental space, as well as reducing amount of injections when compared to mechanical intraligamental syringes.

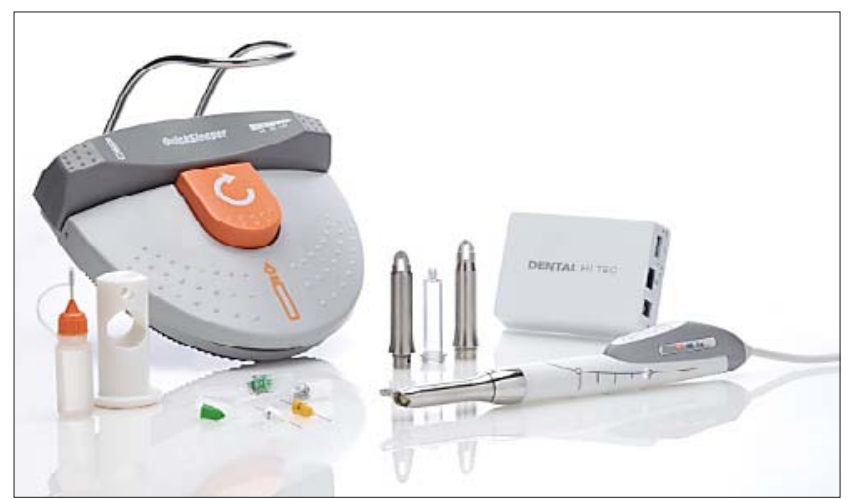

Figure 2. Quicksleeper system (Dental HiTec) [21]

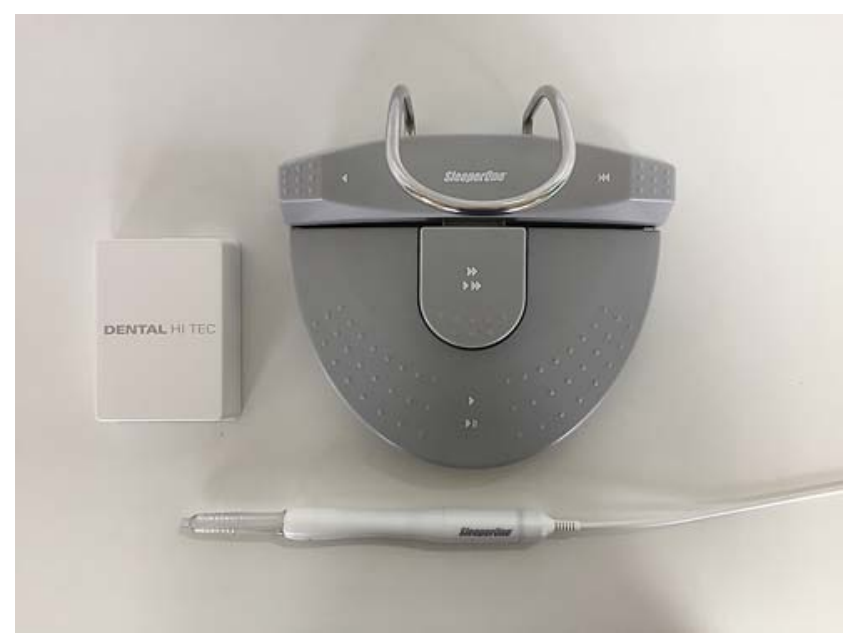

Figure 3. Sleeperone system (Dental HiTec) [22] 
Vibrotactile devices and the Gate-control theory. Vibratory stimulation is one of the non-pharmacological techniques used in pain reduction. The brain is only able to perceive one type of sensation from one area in any given time, therefore, when using vibratory stimulation in local anesthesia, that sensation will reach the brain before the pain sensation. Many devices have been developed to take advantage of the 'Gate-control' theory, which suggests that when applying pressure and using vibration, the neural gate can be closed, thereby reducing the perception of itch and pain [23].

Vibraject. A small, battery-operated device that is attached to the standard dental syringe to deliver high frequency vibrations to the needle [2] (Fig. 4).

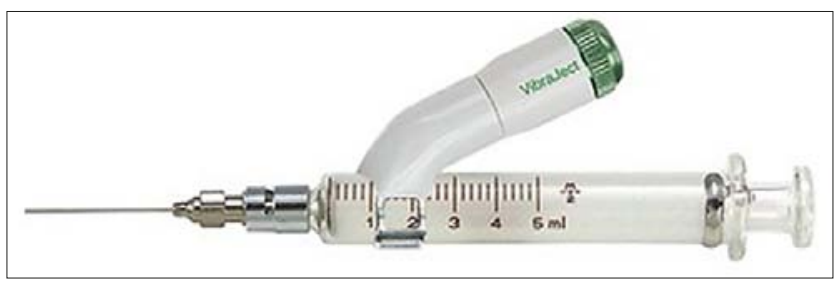

Figure 4. Vibraject system [23]

DentalVibe. A cordless hand-held device that works by delivering smooth, pulsating micro-oscillations to the location where the injection is being administered [2].

Accupal. A cordless device that preconditions the oral mucosa by applying pressure and vibrations to the injection site, after which the needle is placed through a hole in the head of the disposable tip attached to the motor [2].

Syringe micro-vibrator (SMV). The SMV motor provides high frequency vibrations that alleviate pain, and its low vibration altitude ensures that the dexterity of the practitioner and accuracy of the injection isn't are not ffected. This allows the dentist to perform an accurate pain-free injection. The SMV also reduces the ballooning effect that occurs due to a forceful injection under high pressure, which may lead to swelling or other complications after completing the treatment. The vibrations reduce the size of this balloon effect by enhancing tissue infiltration of the anaesthetic solution. Also, the use of SMV eliminates the need and saves the time required for application and onset of topical anaesthetics [23].

Infiltrative techniques. Infiltration is the choice to provide anaesthesia to the maxillary teeth, as well as the mandibular incisors, canines and all teeth, including mandibular molars, in children up 5 years old [11]. Maxillary teeth may be anaesthetised by the infiltration technique, regional nerve block, intraligamentary, intrapulpal and intraosseous anaesthesia. The main branches of the trigeminal nerve (more specifically the maxillary nerve) that are of importance in the upper jaw in anesthesia are: the greater and lesser palatine nerves, the posterior, middle and anterior superior alveolar nerves and the infraorbital nerve. The cortical bone is relatively thin on the outer surface of the upper jaw, which allows for the diffusion of the LA to anaesthatise the buccal roots. The palatal roots are anesthatised by infiltration of the anaesthetic to the greater palatine nerve and nasopalatine nerve branches. High tuberosity nerve block can also be used to anaesthatise the maxillary nerve in surgical situations [11].
Posterior Superior Alveolar (PSA) infiltration. This technique is used to anaesthatise the maxillary molars and the neighbouring buccal soft tissue, as well as the PDL, bone and periosteum. The mesiobuccal aspect of the first molar is not anaesthetized very well with this technique. The point of entry for this injection is at the height of the buccal vestibule, slightly distal to the zygomatic process [1].

Middle Superior Alveolar (MSA) infiltration. MSA infiltration is used to anaesthatise the mesiobuccal aspect of the first molar, premolars and the surrounding buccal soft tissue, bone, PDL and periosteum. The point of entry for this injection is lateral to the maxillary second premolar at the height of the buccal vestibule. The needle is inserted at a depth of around $5 \mathrm{~mm}$, after careful aspiration, introduction of $1.0 \mathrm{ml}$ anesthetic solution follows [1].

Anterior Superior Alveolar (ASA) infiltration. ASA infiltration anaesthetises teeth from canine to the midline teeth, as well as the surrounding buccal soft tissue, PDL, bone and periosteum. The technique of injection is similar to an MSA injection; however, the point of entry is over the maxillary canine. Following careful aspiration, deposition of $1.0 \mathrm{ml}$ of the solution follows [1].

Intraligamentary. This technique is used to achieve anaesthesia for teeth and molars of deciduous dentition as well as permanent teeth. The needle is inserted through the gingival sulcus on the mesial aspect of the tooth as far as possible; approximately $0.2 \mathrm{ml}$ of anaesthetic solution is deposited for at least 20 seconds. The same is performed for the distal aspect of the tooth. The anaesthetic solution diffuses across the alveolar wall into the intraossal space and subsequently the nerve is blocked. Examples of intraligamentary devices are Citoject or Paroject. High pressure develops in the PDL, and there are theories stating that the use of this technique in deciduous teeth may have an impact on the development of the permanent teeth $[1,11]$.

Intraosseous injections. Used when conventional block or infiltration techniques are not effective. They are used to anaesthetise a single tooth or multiple teeth in a quadrant. For many years, the intraosseous technique involved using a round bur to drill and provide entry to the interseptal bone. Today, special devices have been produced, such as the Stabident System (Fairfax Dental, Inc., Miami, FL, USA) to ease this technique. This device uses a slow-speed handpiece perforator with a needle that drills a small hole through the cortical plate, through which the anaesthetic solution is subsequently delivered. The X-tip (Dentsply, Warsaw, Poland) system uses a drill with a guide sleeve. Once the hole is made in the cortical plate, the guide sleeve allows the needle to slide through, and then about $0.6 \mathrm{ml}-1.2 \mathrm{ml}$ is injected. The anaesthetic effect starts working immediately and lasts for 15-45mins [1]. The X-tip has been reported to produce post-operative pain a few days after the procedure, resulting from the heat formation during bone perforation. The manufacturer has withdrawn and stopped producing the X-tip [24, 25].

Intrapulpal. This technique is mainly used during endodontic procedures when conventional anaesthesia is not effective enough. A short needle is inserted into the pulp chamber 
and into the root canal. A small amount of anaesthetic $(0.2-$ $0.3 \mathrm{~mL}$ ) is injected. This technique is not very comfortable for the patient, but it provides effective and quick pain control.

Intraseptal. This technique is particularly useful when attempting to obtain soft tissue, osseous anaesthesia, as well as haemostasis for surgical flap procedures, scaling and root planning. The needle is introduced at a 90 degree angle into the interdental papilla next to the tooth to be treated. The needle is inserted about $2 \mathrm{~mm}$ into the interdental septum, and $0.2-0.4 \mathrm{ml}$ of anaesthetic is injected for at least 20 seconds [1].

Regional nerve blocks. Used to provide anaesthesia over a larger area than other techniques. They are used, among others, in the mandibular arch as infiltrative techniques are not as effective due to increased bone density. Basic nerve block techniques are:

Maxillary nerve blocks. Techniques used with the aim of anaesthetizing half of the maxilla, allowing for various types of surgical treatment to be performed on the maxilla and maxillary sinus. It may also be used to counteract pain that patients may feel for particular reasons [11]. Anaesthesia may be achieved by using the High Tuberosity Anaesthesia Technique or the Greater Palatine Nerve Block.

High tuberosity anaesthesia. Involves the insertion of a $35 \mathrm{~mm}, 25$-gauge needle at a 45 -degree angle superiorposteriorly to the maxillary tuberosity; more specifically, into the pterygopalatine fossa. After aspiration and deposition of one cartridge, half of the upper jaw will become anaesthetized. The maxillary nerve exits the skull through the foramen rotundum running through the pterygopalatine fossa, through the orbit as the infraorbital nerve, and then exits through the infraorbital foramen. Using this technique carries the risk of intravasal injection of the anaesthetic solution into the pterygoid plexus, resulting in a haematoma [11].

Greater palatine foramen block. The entrance to the greater palatine foramen is usually located $1 \mathrm{~cm}$ palatinally between the $2^{\text {nd }}$ and $3^{\text {rd }}$ Molar. It can be palpated as a soft spot on the hard palate. Once found, the needle should be slightly bent approximately 45 degrees and inserted into the foramen. After careful aspiration, slow deposition of $0.5 \mathrm{ml}$ anaesthetic solution is recommended. This technique anesthetizes the tissues of the hard palate laterally, up to the midline, and anteriorly to the distal aspect of the canine [1]. A sideeffect of this type of anaesthesia, in the case of a patient with a small maxilla, the anaesthetic solution may reach the parasympathetic sphenopalatine ganglion, resulting in diplopia (double vision) or blurred vision [11].

Infraorbital nerve block. Supplies sensation to the nostril, lower eyelid, upper lip, unilateral cheek, gingiva and maxillary frontal teeth. There are three methods to provide anaesthesia to the infraorbital nerve. One involves inserting the needle $1 \mathrm{~cm}$ vestibularly to the upper canine in the direction of the pupil. In this method, the index finger of the non-injecting hand rests on the infraorbital rim preventing the needle from touching the eyelid or eyeball. After aspiration, half a cartridge is deposited slowly. Another method is where the needle is inserted between the upper premolars along the long axis of their roots into the buccal sulcus, roughly $2 \mathrm{~cm}$ deep, until it contacts the bone at the level of the infraorbital foramen. This method is generally safe and effective; however, there is a risk of damaging a vein or artery that may result in a haematoma [11]. The third method is an extraoral method. The infraorbital foramen is located on the skin at the intersection of a horizontal line extending approximately $0.8 \mathrm{~cm}$ below the lower edge of the eye socket, and a vertical line passing through the centre of the pupil. After disinfecting the skin, the eyeball is protected against penetration, resting the index finger of the left hand on the lower edge of the eye socket and the thumb rests on the skin fold on the cheek. The needle is introduced at a depth of roughly $0.5 \mathrm{~cm}$ until bone contact. Introducing the needle at an angle allows one to reach the infraorbital foramen. The needle is withdrawn slighty in order to make sure its not in a vessel, and after aspiration $1.5 \mathrm{ml}$ of anaesthetic is deposited [26].

Nasopalatine nerve block. This anaesthetizes the palatal tissue of the premaxilla. The nasopalatine nerve runs through the incisive canal to the incisive papilla, and provides sensation to the anterior $1 / 3$ of the palate. The entrance to the nasopalatine foramen is roughly posterior to the maxillary incisors. This is usually a painful injection, so a good way to perform this anaesthesia is to initially deposit $0.3 \mathrm{ml}$ of local anaesthetic in the maxillary anterior midline. This is followed by introducing the needle carefully, roughly $1 \mathrm{~cm}$ into the nasopalatine canal, and after aspiration $0.25-0.5 \mathrm{ml}$ of anaesthetic solution is deposited [1].

Inferior alveolar nerve block. Allows anaesthetising the mandibular teeth from the third molar to the midline, the lower lip and chin, buccal soft tissue anteriorly to the premolars, the PDL and periosteum. A long, $35 \mathrm{~mm} 27$-gauge needle is required to perform this technique. The needle is inserted approximately $25 \mathrm{~mm}$ from the contralateral premolar area, roughly $1.5 \mathrm{~cm}$ above the mandibular occlusal plane between the pterygomandibular raphe and the deep tendon of the temporalis muscle, until bone contact. The needle should be withdrawn 1-2 mm, and after careful aspiration $1.5 \mathrm{ml}$ of solution is deposited. The lingual nerve is also anaesthetized in this technique as the needle is being removed half-way $(10 \mathrm{~mm})$ while still injecting the solution [1].

Gow-Gates nerve block. This technique was first published in 1973. The advantage of this technique over the standard inferior alveolar nerve block is its higher success rate in anaesthesia, and its lower risk of positive aspiration. This injection anaesthetises the inferior alveolar, lingual, buccal, auricotemporal and mylohyoid nerves. It is performed by initially asking the patient to open the mouth as wide as possible to rotate and translate the condyle forward. The condyle is then palpated by the dental practioner's thumb, and the needle is introduced from the contralateral canine and punctures the mucosa at the height of the occlusal plane of the maxillary second molar. The needle is inserted about 25-30 mm until contact with bone is felt. The needle is then withdrawn 1-2 mm, and after aspiration, slow deposition of the whole cartridge of the anaesthetic solution follows $[1,11]$.

Mental nerve block. The mental foramen exits the mental foramen roughly 5-8 $\mathrm{mm}$ below the lower premolars, 
between their apices. It provides innervation to the skin of the chin, lower lip and buccal mucosa. This technique involves injecting the needle roughly $1.5 \mathrm{~cm}$, after aspiration, one third to one half of the cartridge should be deposited [1].

Techniques for increasing comfort during injection of local anesthetics. Many studies have been performed to find factors that improve patient comfort during the deposition of local anesthetics. It is claimed that warming the local anesthetic diminishes pain during the injection; however, there is also conflicting evidence. Some research has shown that warming the cartridges to body temperature $\left(37^{\circ} \mathrm{C}\right) \mathrm{did}$ not significantly reduce the pain associated with intraoral injections [1]. Overheating the local anaesthetic may result in discomfort to the patient during deposition of the LA, as well as destruction of the heat-labile vasoconstrictor, which results in the shorter action of the anaesthetic [1]. It has also been proved that once the warmed-up cartridge has been placed into the metal syringe, it cools. The anaesthetic cools down to room temperature once the agent flows through the fine metal needle. Another method attempting to increase patient comfort is buffering. LA solutions without vasoconstrictors have a $\mathrm{pH}$ of around 6.5. Once a vasoconstrictor, e.g. epinephrine, as well as the antioxidant sodium bisulfite is added, the $\mathrm{pH}$ lowers to 3.4. Inside the cartridge of the LA, 2 ionic forms exist: the tertiary form unionised (B) and the quaternary form ionised $(\mathrm{BH}+)$. The unionised tertiary form (B) is more lipid soluble that the ionised quaternary form $(\mathrm{BH}+)$. Therefore, the unionised form $(\mathrm{B})$ of the drug is able to diffuse across the lipid-rich nerve membrane, where it picks up a $\mathrm{H}+$, and subsequently is converted into the quaternary form of the drug $(\mathrm{BH}+)$ which enters the sodium channel and blocks the nerve conduction. Once the LA is injected into the tissues, the buffering process begins. The $\mathrm{pH}$ of tissues is around 7.4. When a LA with a lower $\mathrm{pH}$, such as 3.5, is injected into the tissues, the body's natural ability to buffer will slowly increase the $\mathrm{pH}$ of the injected solution to 7.4. During this process, the concentration of the unionised (B) molecules in the solution increases, which means more B molecules are available to enter the nerve and theoretically provide a greater anaesthetic effect. Recent technical advances have shown that alkalization of the LA cartridges prior to injection reduces injection pain [1]. If the $\mathrm{pH}$ of the LA solution were to be increased to 7.4 before the injection, both speed of onset and patient comfort would improve during the injection. Generally, LAs with a lower $\mathrm{pH}$ of around 3.5 produce a 'burning' sensation as soon as its deposited into the tissues. LAs with a higher $\mathrm{pH}$ are more readily accepted by patients [1]. In medicine, sodium bicarbonate is used as a buffer by surgeons when administering the LA into the skin to alleviate the pain associated with the injection. There, however, mixed findings about the efficacy of sodium bicarbonate as a buffer, since there is a big variation in $\mathrm{pH}$ of the sodium bicarbonate solution. Its $\mathrm{pH}$ ranges from 7.0-8.5 [1].

Local Anesthetics Reversal - OraVerse. Many dental patients complain of the prolonged soft tissue anaesthesia which inhibits their normal oral function and leads to selfinflicted injuries. In May 2009, OraVerse (phentolamine mesylate) was approved by the FDA. It is the first and only local dental anaesthesia reversal agent available on the market. The OraVerse solution is injected by the dentist into the area of the patient's mouth that is already numb.
Once OraVerse is administered, the numbness recovery of the patient is halved. It works by increasing the diameter of blood vessels in the area of numbness. Subsequently, this increases the blood flow to that area and, as a result, the anaesthetic solution is removed and transported to the liver and kidneys to be broken down. The recommended dose of OraVerse is two cartridges for patients aged 12 or more, one cartridge in children age 6-11 years and weighing over $29 \mathrm{~kg}$. OraVerse is not indicted for children aged less than 6 years, or weighing less than $15 \mathrm{~kg}$. It is also inadviseable to use it after invasive surgical procedures or endodontic treatments, where post-operative discomfort is expected [27].

\section{CONCLUSION}

Over the past 50 years or so, huge advances in knowledge and research into local anaesthetics have provided dental practitioners with new techniques and agents that are safer to administer to their patients. In return, the patients themselves experience significantly reduced pain during the injection, which provides more comfort and a less stressful experience when visiting the dentist.

\section{REFERENCES}

1. Reed KL, Malamed SF, Fonner AM. Local Anesthesia Part 2 Technical Considerations. Anesthesia Progress. 2012; 59 (3): 127-137. doi:10.2344/0003-3006-59.3.127

2. Saxena P, Gupta SK, Newaskar V, Chandra A.: Advances in dental local anesthesia techniques and devices: An update., National Journal of Maxillofacial Surgery. 2013; 4(1): 19-24. doi:10.4103/0975-5950.117873

3. Becker DE, Reed KL. Local Anesthetics: Review of Pharmacological Considerations. Anesthesia Progress. 2012; 59(2): 90-102. doi:10.2344/0003-3006-59.2.90

4. Maruthingal S, Mohan D, Maroli RK, Alahmari A, Alqahtani A, Alsadoon M. A comparative evaluation of $4 \%$ articaine and $2 \%$ lidocaine in mandibular buccal infiltration anesthesia: A clinical study. Journal of International Society of Preventive \& Community Dentistry. 2015; 5(6): 463-469. doi:10.4103/2231-0762.167717

5. Bajwa SJS, Jindal R. Use of Articaine in loco-regional anesthesia for day care surgical procedures. Journal of Anaesthesiology, Clinical Pharmacology. 2012; 28(4): 444-450. doi:10.4103/0970-9185.101898

6. Balakrishnan K, Ebenezer V, Dakir A, Kumar S, Prakash D. Bupivacaine versus lignocaine as the choice of locall anesthetic agent for impacted third molar surgery a review. Journal of Pharmacy \& Bioallied Sciences. 2015; 7(Suppl 1): S230-S233. doi:10.4103/0975-7406.155921

7. Su N, Liu Y, Yang X, Shi Z, Huang Y. Efficacy and safety of mepivacaine compared with lidocaine in local anaesthesia in dentistry: a metaanalysis of randomised controlled trials. Int Dent J. 2014; 64: 96-107. doi:10.1111/idj.12087

8. Laura J. Webb, RDH, MS, CDA; Dental anesthesia: Overview of injectable agents useful for nonsurgical periodontal therapy' January 12, 2016; http://www.rdhmag.com/articles/print/volume-36/issue-1/ contents/understanding-available-agents.html

9. Lauren L. Gutenberg, Jung-Wei Chen, and Larry Trapp. Methemoglobin Levels in Generally Anesthetized Pediatric Dental Patients Receiving Prilocaine Versus Lidocaine. Anesthesia Progress: Fall 2013, Vol. 60, No. 3, pp. 99-108.

10. Biomed Pap Med Fac Univ Palacky Olomouc Czech Repub. 2016 Dec; 160(4): 571-577. doi: 10.5507/bp.2016.040. Epub 2016 Aug 2. The impact of cardiovascular drugs on the efficacy of local anesthesia in dentistry. Milosavljevic MJ1, Jankovic SM2.

11. Baart JA. Local anaesthesia in dentistry. 5th ed. St Louis,UK: Wileyblackwell; 2009. p. 75-103.

12. Malamed SF, Daniel L. Handbook of Local Anesthesia. 5th ed. St Louis, MO: Mosby; 2004. p. 79.

13. EB Medicine: Fixing Faces Painlessly: Facial Anesthesia In Emergency Medicine; Benko K. December 2009, Volume 11; Number 12. https:// www.ebmedicine.net/topics.php?paction=showTopic\&topic_id=207 
14. Becker DE. Adverse Drug Reactions in Dental Practice. Anesthesia Progress. 2014; 61(1): 26-34. doi:10.2344/0003-3006-61.1.26

15. Cynthia R. Biron, RDH, MA; Adverse reactions to local anesthetics; http://www.rdhmag.com/articles/print/volume-20/issue-10/ departments/medical-alert/adverse-reactions-to-local-anesthetics.htm

16. Peedikayil FC, Vijayan A. An update on local anesthesia for pediatric dental patients. Anesthesia, Essays and Researches. 2013; 7(1): 4-9, doi:10.4103/0259-1162.113977

17. Handbook of Pediatric Dentistry - Mosby; 3rd Edition (August 1, 2008). p.31.

18. Beneito-Brotons R, Peñarrocha-Oltra D, Ata-Ali J, Peñarrocha M. Intraosseous anesthesia with solution injection controlled by a computerized system versus conventional oral anesthesia: A preliminary study. Medicina Oral, Patología Oral y Cirugía Bucal. 2012; 17(3): e426-e429. doi:10.4317/medoral.17543

19. SleeperOne information http://www.sleeperone.pl

20. Tom K, Aps J. Intraosseous Anesthesia as a Primary Technique for Local Anesthesia in Dentistry. Clin Res Infect Dis. 2015; 2(1): 1012.
21. Image taken from dentalhitec.com: http://www.dentalhitec.com/2015/ produits/quicksleeper

22.JUNG, R 2017. Personal Photograph of SleeperOne device.

23. Shahidi Bonjar AH. Syringe micro vibrator (SMV) a new device being introduced in dentistry to alleviate pain and anxiety of intraoral injections, and a comparative study with a similar device. Annals of Surgical Innovation and Research. 2011; 5:1. doi:10.1186/1750-1164-5-1

24. Image taken from dental-tribune.com: http://www.dental-tribune.com/ products/161_vibraject-the_multiple-use_dental_needle_accessory_ for_endodontic_procedures.html

25. Clark TM, Yagiela JA. Advanced techniques and armamentarium for dental local anesthesia. Dent Clin North Am. 2010; 54: 757-68. [PubMed]

26. Stanisław B. Bartkowski (red.) Chirurgia Szczękowo-Twarzowa, ed. III, Collegium Medicum UJ, Krakow 1996. p. 92.

27. Prasanna JS. OraVerse: Reverses Numbness After Dental Procedures. Journal of Maxillofacial \& Oral Surgery. 2012; 11(2): 212-219. doi:10.1007/s12663-011-0318-6. 